\title{
Q Versatile Seismic Imager (QVSI) Successfully Predicts Target Depth and Pore-Pressure in HPHT Environment
}

\author{
Ming Chen', Guimei Pan², Shiyue Wang1, Dianqiang Sun'1, Chao Du1 \\ ${ }^{1}$ CNOOC China Ltd., Zhanjiang, China \\ ${ }^{2}$ Cunjin College of Guangdong Ocean University, Zhanjiang, China \\ Email: 2891010029@qq.com
}

How to cite this paper: Chen, M., Pan, G.M., Wang, S.Y., Sun, D.Q. and Du, C. (2017) Q Versatile Seismic Imager (QVSI) Successfully Predicts Target Depth and PorePressure in HPHT Environment. Engineering, 9, 241-250.

https://doi.org/10.4236/eng.2017.92011

Received: August 17, 2016

Accepted: February 25, 2017

Published: February 28, 2017

Copyright $\odot 2017$ by authors and Scientific Research Publishing Inc. This work is licensed under the Creative Commons Attribution International License (CC BY 4.0).

http://creativecommons.org/licenses/by/4.0/ (c) (i) Open Access

\begin{abstract}
Drilling in any environment is challenging as it poses a challenge to drill reservoir targets without losses and minimum casing strings and is even challenging in HPHT (high pressure high temperature) environment. Seismic is the fundamental for pre-drill prognosis and completion design. The target depth prognosis is achieved through depth transformation by using seismic velocities or available velocity logs in the nearby field or block and often has varying degree of uncertainty in target depths depending upon the suitable of the velocity function used. The velocity function used could be affected due to available seismic bandwidth or structure. These uncertainties in target depths often lead to increased well costs as a result of wellbore stability issues \& undesired casing strings. Most common issue faced by drillers is the target confirmation \& distance to these targets ahead of bit. Vertical seismic profile (VSP) look-ahead at intermediate depths is one of the approaches to mitigate these uncertainties and drill wells safely. VSP help confirm the presence of drilling targets $\&$ also predict the depth to top of these targets. Additionally, the predicted interval velocity is used to predict the pre-pressure for next section drilling. In South China Sea, oil \& gas operators face a significant risk while drilling over-pressured formations. It is therefore imperative to know the depth to top of these high pressured formations to avoid drilling directly into it and risking the well. It is also important to know the pore-pressure and mud weight for the next section to be drilled for safe drilling \& with minimum casing strings [1] [2] [3]. It is more difficult to get this information in the HPHT environment due to the lack of high temperature tools [4]. Schlumberger's proprietary QVSI ${ }^{\star}$ - High pressure, high temperature VSI* (Versatile Seismic Imager) has been successfully used to predict the target depth for casing landing and pore-pressure prediction in HPHT environment. QVSI is the latest generation of $\mathrm{VSI}^{*}$ Versatile Seismic Imager tools developed by
\end{abstract}


Schlumberger to acquire high quality tri-axial borehole seismic data in extreme environment wells. The QVSI* tool uses the Q-Technology* singlesensor hardware and software and advanced wireline telemetry for fast digital seismic data transmission from borehole to surface. QVSI is a high-temperature, high-pressure array tool design that focuses on tri-axial vector fidelity and efficient data acquisition, extending the limits in a 4-tool configuration to $500^{\circ} \mathrm{F}\left(260^{\circ} \mathrm{C}\right)$ and $30 \mathrm{kpsi}(207 \mathrm{MPa})$. In this paper, a case study is presented for Well-XX for CNOOC from South China Sea. The well-xx is located in Yanyan Sag, Qiongdongnan Basin and the downhole temperature was $204^{\circ} \mathrm{C}$. The main target layer is Lingshui III sandstone, which is controlled by Northwest fault. It is a gas well and critical for the client to land the casing at right depth and know the drilling parameters for the next section ahead. QVSI* predicted the target depth within $\pm 2 \mathrm{~m}$ for decision on casing point. The predicted pore pressure was within $\pm 0.1 \mathrm{ppg}$.

\section{Keywords}

Pore-Pressure Prediction, HPHT, QVSI

\section{Introduction}

Qiongdongnan Basin (Figure 1) is a Cenozoic rift basin located on the northern passive continental margin of the South China Sea. Due to a lack of geologic observations, its evolution was not clear in the past. However, recently acquired seismic data provide an opportunity to investigate its tectonic evolution. It shows that the Qiongdongnan Basin comprises a main rift zone which is 50 - 100 $\mathrm{km}$ wide and more than $400 \mathrm{~km}$ long. The main rift zone is arcuate in map view and its orientation changes from ENE-WSW in the west to nearly E-W in the east. The HPHT environment further makes things complex from drilling perspective.

The well-xx is a clastic reservoir with gas being the main hydrocarbon. The well is displayed along with seismic in Figure 1. The well is assumed to be going through the over-pressured formations. Hence it was imperative to know the depth of the target layer accurately to lower the casing at the optimum position and also predict the pore-pressure and mud weight of the section to be drilled. VSP is one of few technologies that is helpful in predicting the depth to target layers. The VSP is inverted to derive acoustic impedance profile and interval velocity ahead of bit which used for depth prediction. Pore-pressure also manifests itself in drop in velocity across the formation, hence the inverted velocity is transformed into pore-pressure estimation and mud weight prediction.

\section{Methodology}

Vertical Seismic Profile (VSP) is the only technology that provides look-ahead capability for safe drilling. The sensor is deployed downhole and source fired at the surface. The sensor records the direct and reflected arrivals along with other 

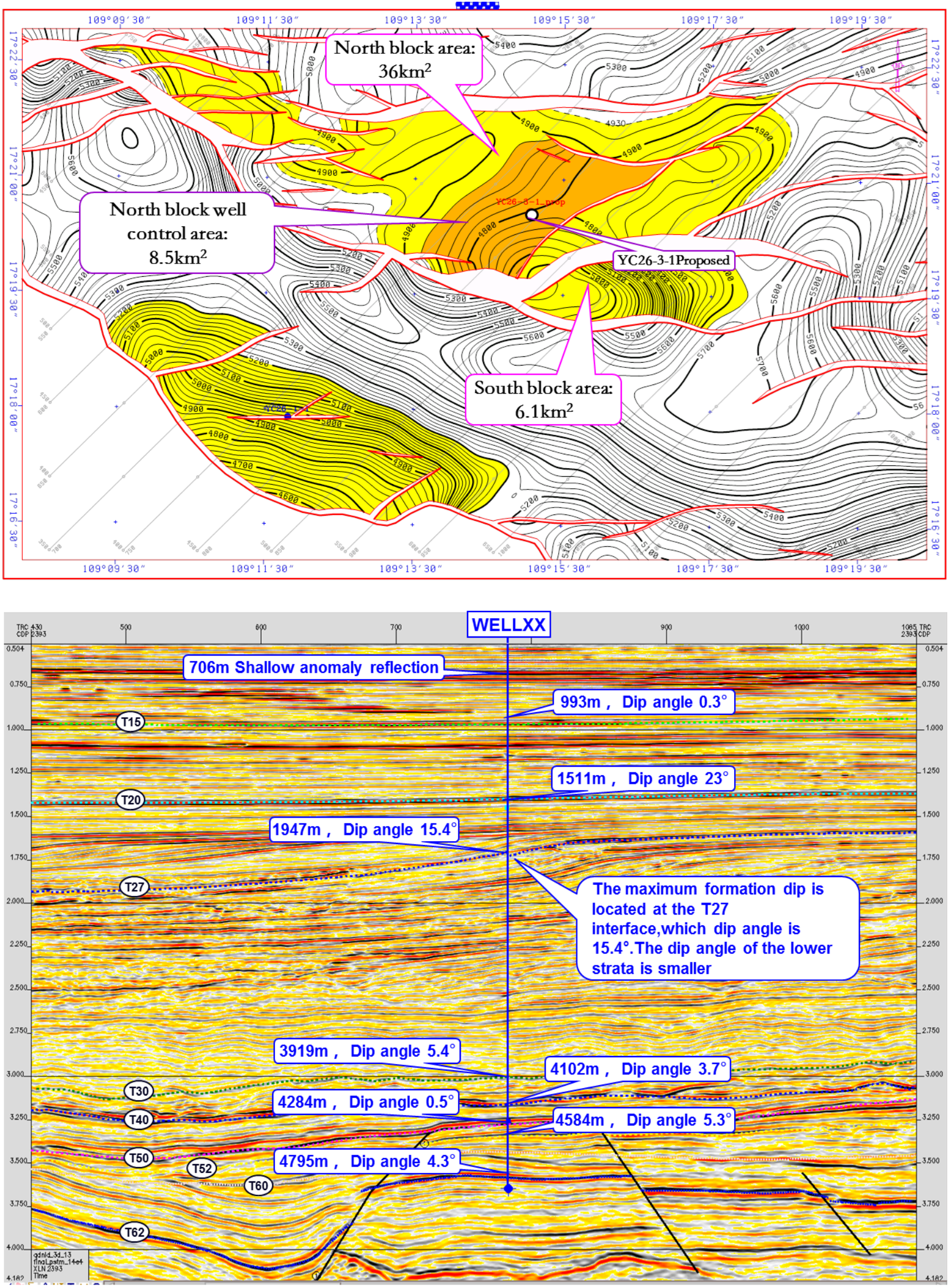

Figure 1. Left: (Lingshui III) structure \& surface seismic (right). 
propagation modes. The direct arrivals provide the time-depth \& velocity information in the well while the reflected arrivals provide the seismic response at the well for seismic correlation. The end product is a corridor stack that can be directly be compared with surface seismic for correlation and target layers identification. VSP records reflections from below the bit and hence is a suitable tool for look-ahead prediction. VSI* (Versatile Seismic Imager) is state of art technology downhole tool has provided hi-fidelity tri-axial component data in the conventional temperature environment.

In HPHT environment, $\mathrm{QVSI}^{*}$ is the latest generation of $\mathrm{VSI}^{*}$ Versatile Seismic Imager tools developed by Schlumberger to acquire high quality tri-axial borehole seismic data in extreme environment wells. The QVSI* tool uses the Q-Technology* single-sensor hardware and software and advanced wireline telemetry for fast digital seismic data transmission from borehole to surface. QVSI is a high-temperature, high-pressure array tool design that focuses on tri-axial vector fidelity and efficient data acquisition, extending the limits in a 4-tool configuration to $500^{\circ} \mathrm{F}\left(260^{\circ} \mathrm{C}\right)$ and $30 \mathrm{kpsi}(207 \mathrm{MPa})$. Figure 2 shows the tool string for QVSI*.

The VSP data provides the down going wavelet and the up going reflection (corridor stack) which can then be processed in the reverse process to derive the reflectivity and acoustic impedance (AI) of the sub-surface. The AI is then transformed to interval velocity ahead of the bit. This inverted velocity is used to predict the depth to top of the target (identified by seismic pick). The target formation is interpreted on surface seismic and used as a reference for depth prediction from the VSP.

Under-compaction of formations is one of the major causes of over-pressured formations and is one of the type of pore-pressure mechanisms. This type of over-pressure can easily be picked by the acoustic measurement as the overpressure manifests itself in drop in velocity as shown in Figure 3. The inverted velocity from VSP is then used to predict the pore-pressure and mud weight for next section drilling. Various transforms are available and can be used for velocity to pore-pressure transform. We integrate the VSP \& Geomechanics to derive the pore-pressure and mud weight. The inverted velocity is combined with Geomechanics and drilling parameters are derived.

\section{Case Study}

The well-xx is drilled in HPHT environment with the downhole temperature

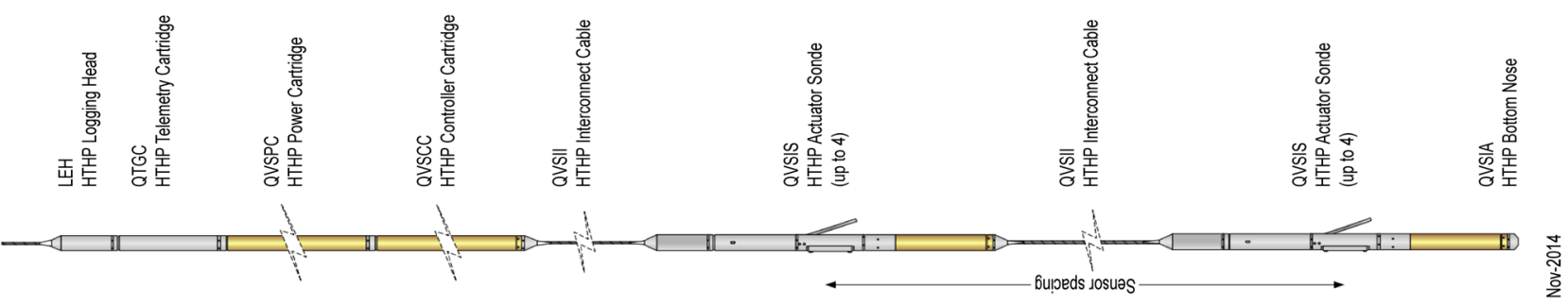

Figure 2. Q Versatile Seismic Imager (QVSI*) tool string. 
close to $204^{\circ} \mathrm{C}$. The client faces a challenge to drilling safely through the overpressured formations in two different sections. It was critical to accurately predict the depth of target layers and predict pore pressure. The VSP data was acquired in two sections in two different runs by using QVSI*. A tri-axial component (XYZ) data with excellent data quality was acquired in both the runs. The combined stack data for two VSP runs is shown in Figure 4. The stack data quality is excellent with clear first break, flat background and excellent repeatability between the two VSP runs. The data shows high frequency bandwidth, with the effective bandwidth $\sim 80 \mathrm{~Hz}$ at total depth of the well. Figure 5 shows the frequency-amplitude spectrum for the combined stack data.

The data is processed by preserving the true amplitude of the data as it will be used for inversion purpose. The VSP data is then subjected to pre-processing comprising of band-pass filter, geometric and datum correction. The preprocessed

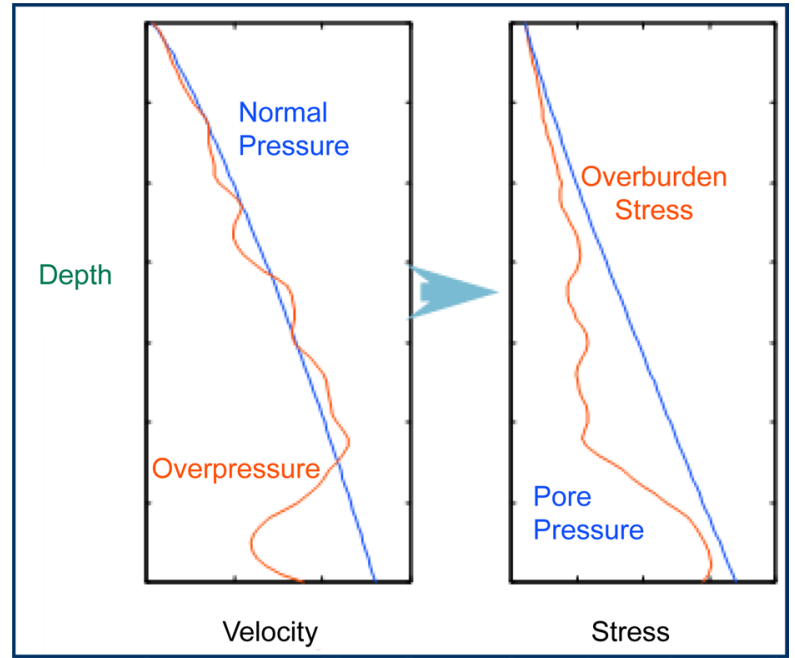

Figure 3. Velocity drop and pore-pressure change in under compaction mechanism.

$\mathrm{X}$

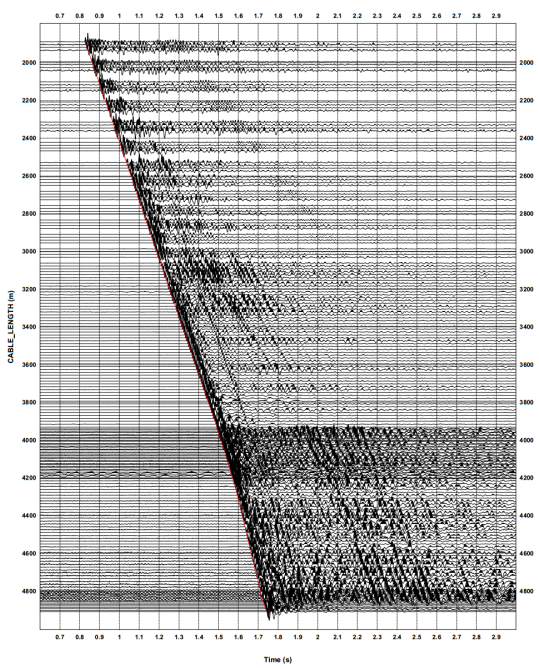

$\mathrm{Y}$

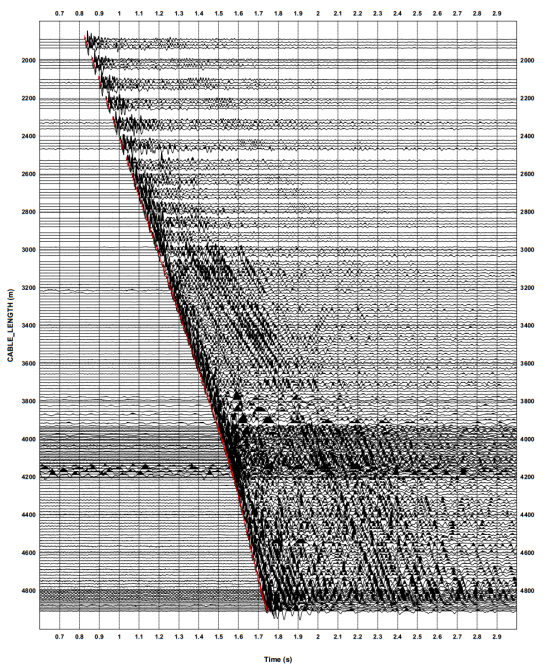

Z

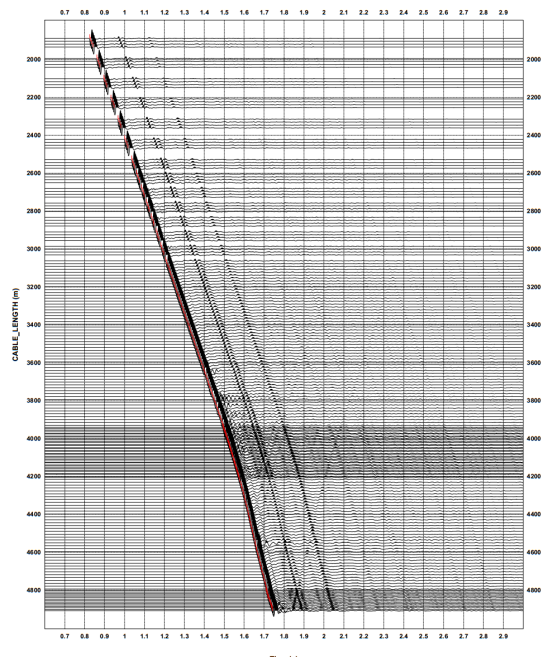

Figure 4. Stack data (XYZ components) for combined two VSP runs. The section in the middle shows the overlap between two runs. 

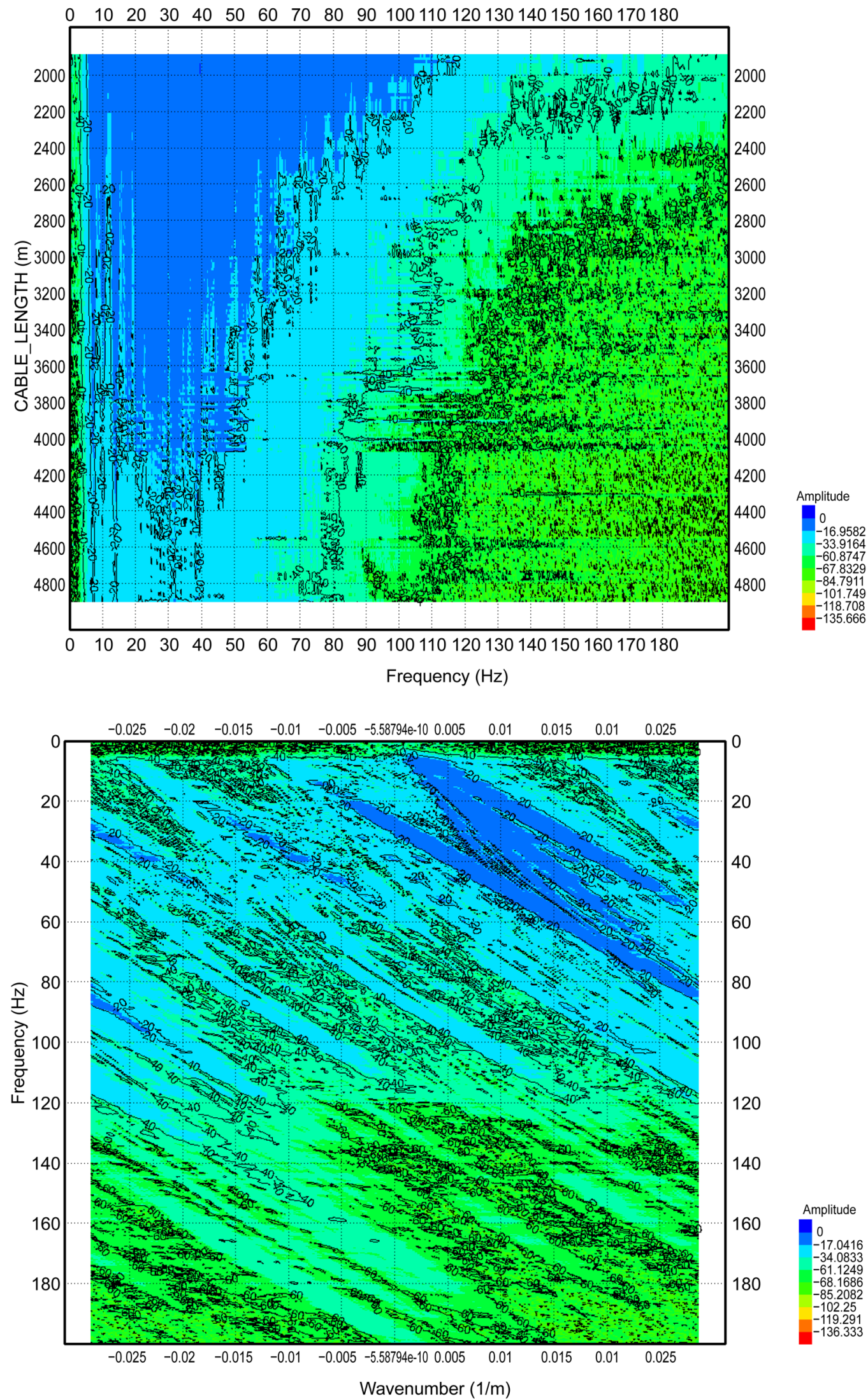

Figure 5. Frequency-amplitude (left) and F-K (right) spectrum for combined stack data. VSP shows frequencies up to $80 \mathrm{~Hz}$ at TD. 
is then separated (downgoing and up going wavefields) by using median velocity filter. The data is then deconvolved (Zero Phase) by using an optimum frequency bandwidth. The final deconvolved up going wavefield is displayed in Figure 6. The up going wavefield shows excellent continuity of events between the two runs.

The VSP \& seismic correlation is shown in Figure 7. The correlation is quiet good and the target event is well identified on the VSP. The target pick on seismic is transported on to VSP and then used as reference for depth prediction. The target layer is identified @3.573 s TWT.

The deconvolved up going wavefield is then inverted to derive the interval velocity ahead of bit. This velocity is then used to predict the depth to the top of target and then integrated with geomechanics to derive the pore pressure. In inversion process the corridor stack is inverted to derive the acoustic impedance and reflectivity. The reflectivity is then convolved with the wavlet and a synthetic is computed. The difference between the actual corridor stack and synthetic is minimized in least square sense. The principle of VSP inversion process is shown in Figure 8. The target layer identified at $3.573 \mathrm{~s}$ TWT corresponds to $5066 \mathrm{~m}$.

The inverted velocity was then integrated with Geomechanics to derive the pore pressure and mud weight ahead of the bit for next section drilling. The inverted velocity used to define the compaction trend and used for pore pressure prediction and mud weight for the next section to be drilled. The predicted well parameters are displayed in Figure 9.

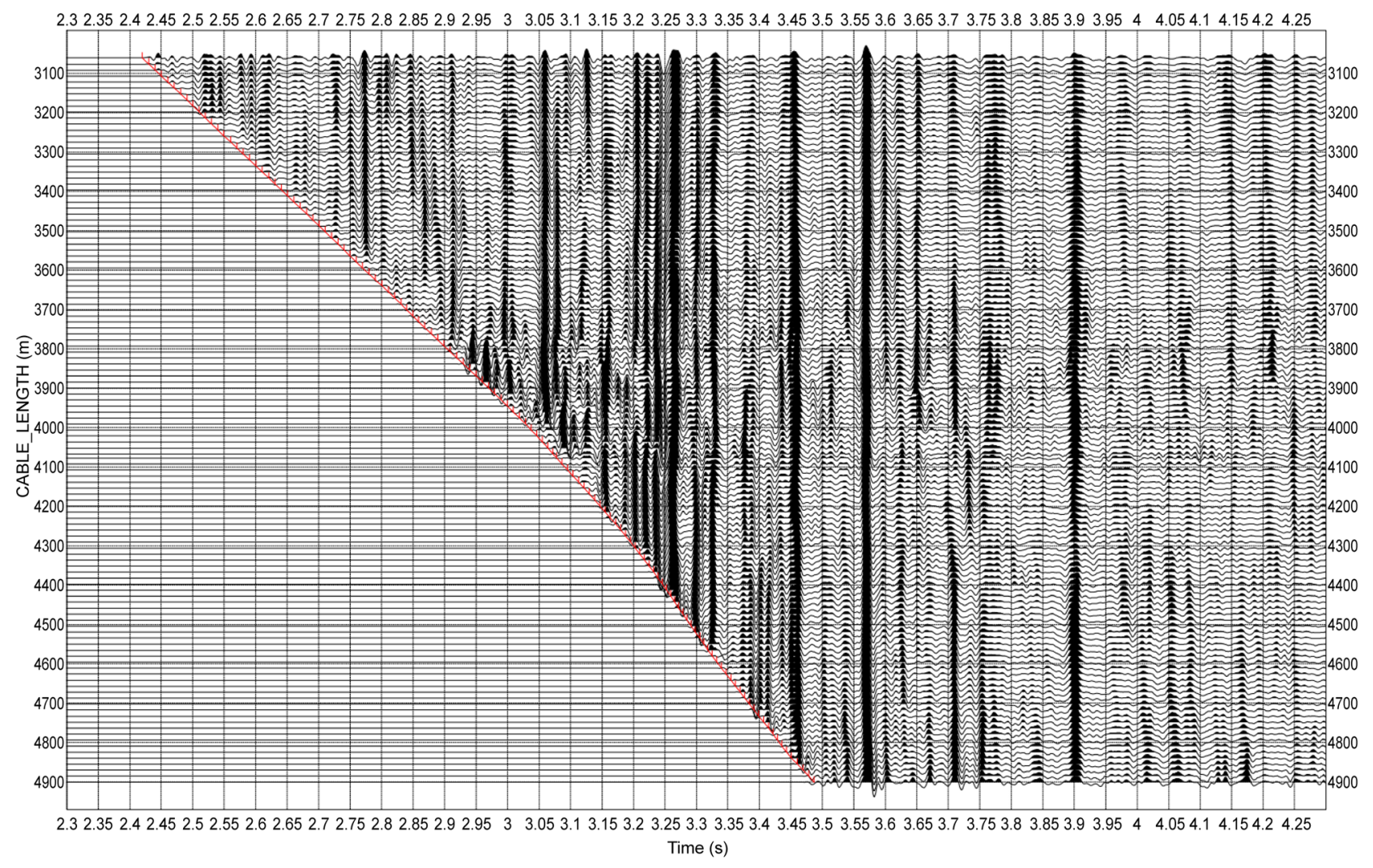

Figure 6. Final deconvolved upgoing wavefield (Zero Phase) and aligned in two way time (TWT). 

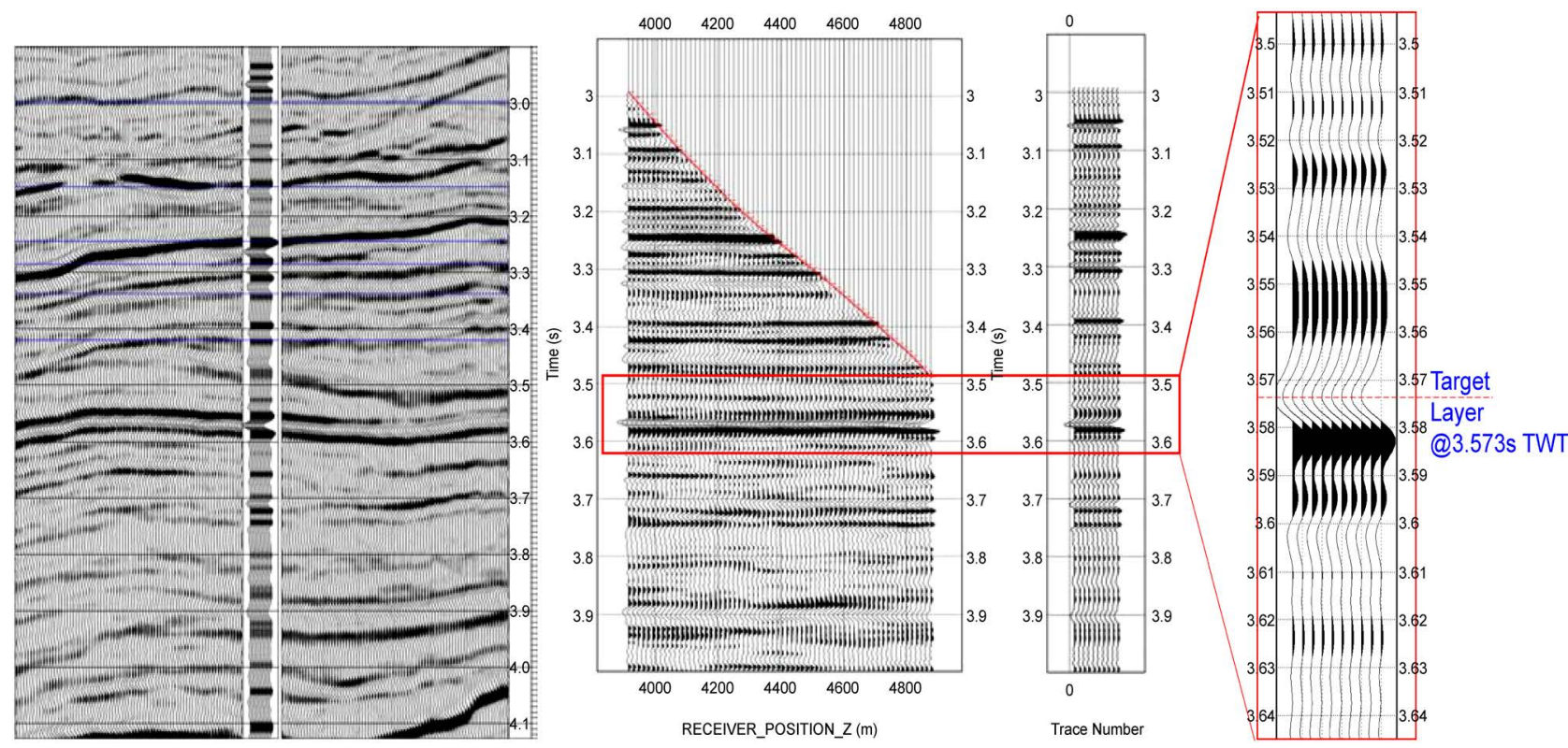

Figure 7. Final deconvolved upgoing wavefield (Zero Phase) and aligned in two way time (TWT). The target layer is identified on VSP data.

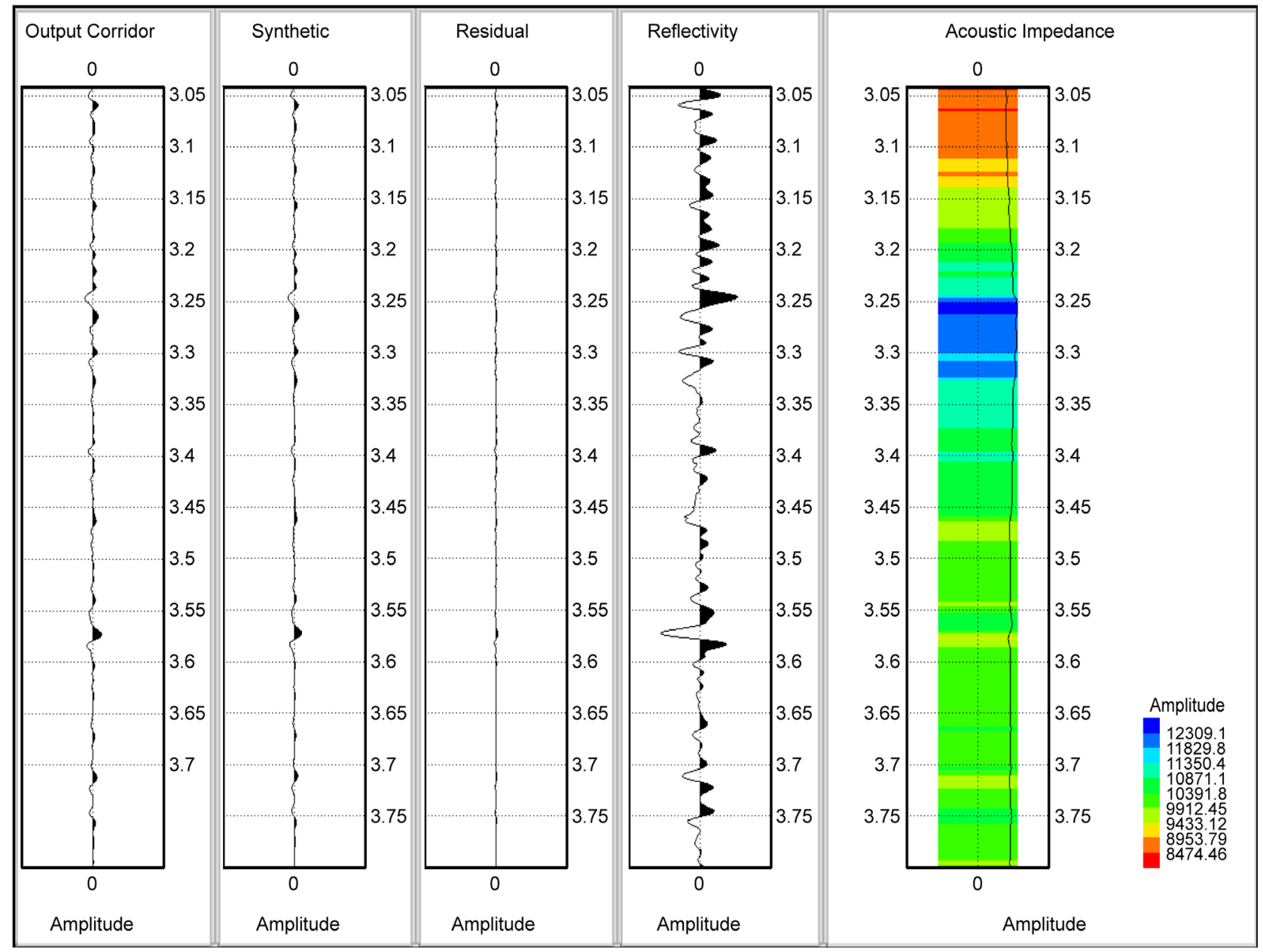

Figure 8. VSP inversion process. It shows the corridor stack, synthetic and the residual between the corridor stack \& synthetic along with reflectivity and acoustic impedance. 


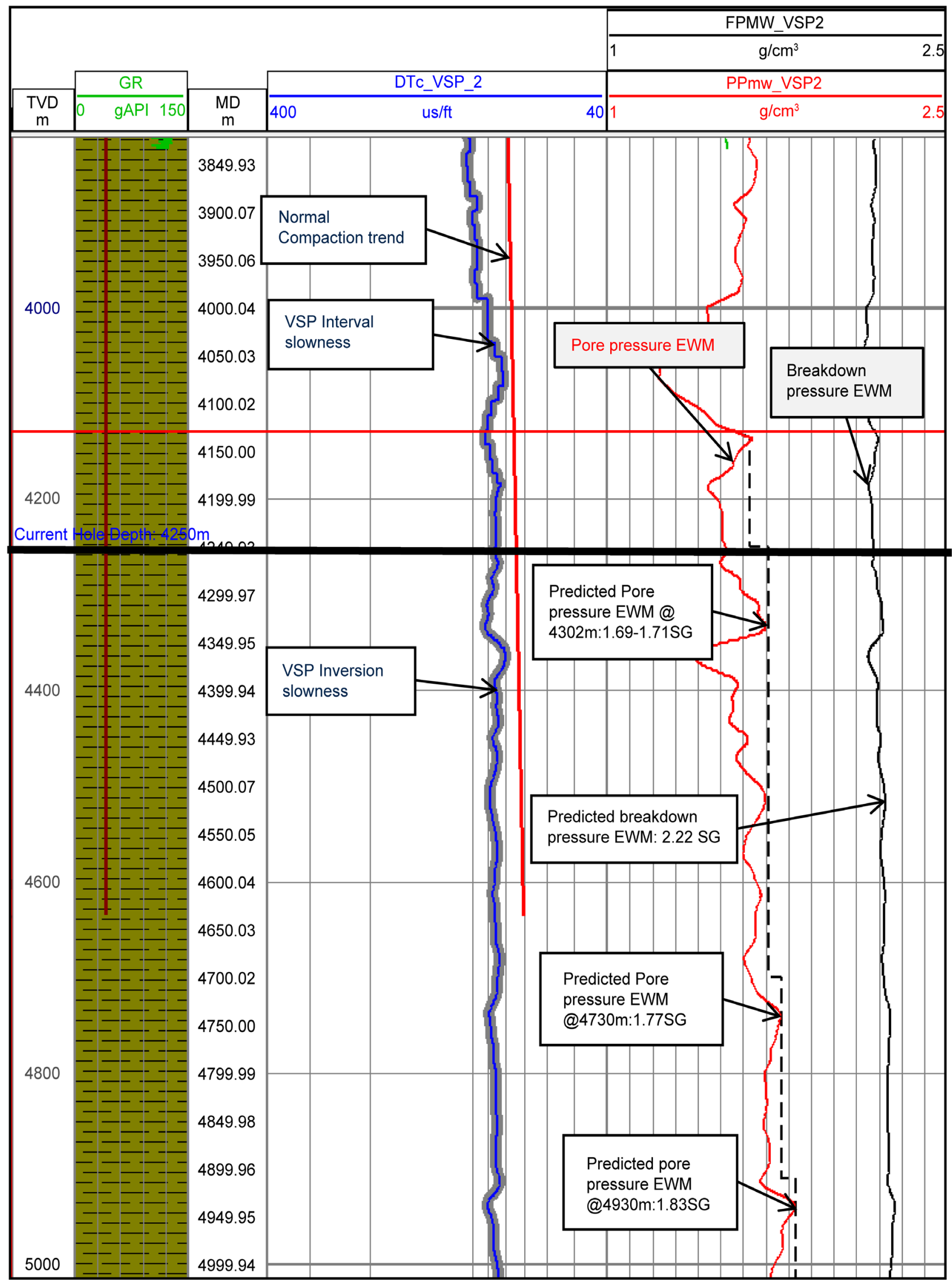

Figure 9. Pore-pressure and mud weight prediction by VSP-Geomechanics integration. 


\section{Results}

The predicted target depth was very close to the actual drilled depth in subsequent drilling. The target formation was drilled within $2 \mathrm{~m}$ of the predicted depth. The mud weight was adjusted based on the predicted parameters and section was drilled without any problems. The pore-pressure in the subsequent drilling is within $\pm 0.1 \mathrm{ppg}$.

\section{Conclusions}

The QVSI* provided excellent VSP data in high temperature environ which provided accurate target depth \& pore pressure prediction ahead of bit. The data were helpful in casing depth optimization and safe drilling. It could be deemed as value addition in relevant real time.

QVSI has been used for the first time in HT environment and has been very successful in look-ahead prediction.

\section{Acknowledgements}

We thank CNOOC for permission to publish this work.

\section{References}

[1] Hardage Bob, A. (1985) Vertical Seismic Profiling Part A: Principles. Geophysical Press.

[2] Tadeusz, J.U., Mauricio, D.S. and Alan, W. (2001) A Bayes Tour of Inversion: A Tutorial. Geophysics, 66, 55-69. https://doi.org/10.1190/1.1444923

[3] Luo, X., Dong, W., Yang, J. and Yang W. (2003) Overpressuring Mechanisms in the Yinggehai Basin, South China Sea. AAPG Bulletin, 87, 629. https://doi.org/10.1306/10170201045

[4] Wydrinski, R., Ramos, G., Weng, X. and Payne, M.L. (1998) Pore Pressure and Stress Gradient Prediction in Geopressured Formations, South China Sea, PRC. Paper SPE 48883 Presented at the International Conference and Exhibition in China. https://doi.org/10.2118/48883-MS 
Submit or recommend next manuscript to SCIRP and we will provide best service for you:

Accepting pre-submission inquiries through Email, Facebook, LinkedIn, Twitter, etc. A wide selection of journals (inclusive of 9 subjects, more than 200 journals)

Providing 24-hour high-quality service

User-friendly online submission system

Fair and swift peer-review system

Efficient typesetting and proofreading procedure

Display of the result of downloads and visits, as well as the number of cited articles Maximum dissemination of your research work

Submit your manuscript at: http://papersubmission.scirp.org/

Or contact eng@scirp.org 